\title{
Bio-Control of Fresh and Dried Portion of Hyptis suaveolens Plant on Mosquitoes Population during Raining Season in Nigeria Police Academy, Kano
}

\author{
Terseer Joseph Hemen, Ali Muhammad Hadiza
}

Department of Biological Science, Faculty of Science, Nigeria Police Academy, Wudil, Nigeria

Correspondence to: T. J. Hemen, hemenjoseph@yahoo.com

Keywords: Hyptis suaveolens, Mosquitoes, Population and Efficacy

Received: October 10, $2019 \quad$ Accepted: November 26, $2019 \quad$ Published: November 29, 2019

Copyright (c) 2019 by author(s) and Scientific Research Publishing Inc.

This work is licensed under the Creative Commons Attribution International License (CC BY 4.0).

http://creativecommons.org/licenses/by/4.0/

(c) (i) Open Access

\section{ABSTRACT}

Comparative study was conducted on fresh and dried portions of Hyptis suaveolens plant, to control mosquito population, and determine which portion has the highest efficacy in killing the vector. The study was conducted in Nigeria Police Academy, Wudil, Kano State Nigeria. The result revealed that both portions of the test plant (Hyptis suaveolens) have toxic effect on mosquitoes. During the study, three (3) experimental units were established and nine (9) sub units were made, three within each of the major units at different locations within the study area. Mosquitoes were reared at all units and various quantities test plant (both fresh and dried portions) were introduced at different quantities and observed at different times of the day (Morning, Afternoon and Evening) within 24 hours in order to test their efficacy on mosquitoes. A total of two hundred and fifty three (253) death rate (DR) with a total \% mortality rate (\% M.R) of 217.9 mosquitoes were recorded from the three different experimental units with the highest \% MR from the cadets hostels. There was a gradual overall mortality rate increase in every experimental unit as the quantity (concentration) of the test plant (Hyptis suaveolens) introduced into the units increased. More so, a resultant highest cumulative death rate of 119 was recorded in the evening. Comparatively, fresh portion of the test plant was more effective for killing the adult mosquitoes during the study. Statistically, it also shows that, there was a strong correlative relationship $(r=0.9832)$ between the quantity (concentration) of the test plant ( $H$. suaveolens) and the death rate of mosquito vectors. 


\section{INTRODUCTION}

\section{Background Information about the Study}

Ethnobotanical studies conducted on African plant species indicate that many of them repel mosquitoes effectively when burned overnight in room, hence seeming to be a desirable approach to malaria control (National control programme in Nigeria, 1997). Despite several efforts in the field of vector control, the medical and economic burden caused by vector-borne diseases continues to grow as current control measures fail to cope [1]. There is therefore an urgent need to identify new control strategies that will remain effective, even in the face of growing insecticide and drug resistance [2,3] included Hyptis suaveolens in their photochemical and ethnobotanical database as an insect repellent. Laboratory study has assessed the repellency rates of various concentrations of $H$. suaveolens essential oil and $6 \%$ of the oil was said to induce a high repellency rates in laboratory conditions [4]. Recent field work conducted with $H$. suaveolens essential oil showed that the effects of a solution containing $8 \%$ of the oil persisted and repelled up to $97.56 \%$ of mosquitoes by 5 hours' post-application [4].

Current vector control strategies include chemical-based control measures, non-chemical based control measures and biological control agents [5]. Chemical-based control measures have dominated over other strategies over the years. [1], reported that repetitive use of man-made insecticides for mosquito control disrupts natural ecosystems and the biological control systems, and lead to reemergence of, and increase in mosquito populations. In their studies, $[6,7]$ also pointed out that the continuous use of chemical-based insecticides has resulted in the development of resistance, detrimental effects on non-target organisms and human health problems. Consequently, they suggested the need for alternative control measures which leaves biological control as a viable alternative measure. The use of biological control agents such as predatory fish [8], bacteria [9], protozoa [10], fungus [11], nematodes [12] and plant products [13], had shown promising results in the control of mosquito populations [14].

In view of the above research problem, there is need for cheaper and safer alternative control practices. Over the years, indigenous people have learned to tackle insects' problems through the use of plant extracts due to their resistance against chemical insecticides. Hyptis suaveolens is one among such plant species used locally in rural areas as repellent for biological control of mosquitoes [15]. Based on the aforementioned challenges, the research work was designed to determine the lethal effect of dried and fresh portions of $H$. suaveolens plant on mosquito population with the hope that a new and more effective product may be developed from it.

\section{MATERIALS AND METHODS}

\subsection{Description of the Study Area}

This research study was conducted at Nigeria Police Academy (Polac) in Wudil Local Government Area Kano State Nigeria, which is located in East Central Area of Kano State, and in the central area of Kano Region between longitude $8^{\circ} 45^{\prime} \mathrm{E}$, as well as between latitude $11^{\circ} 37^{\prime} \mathrm{N}$ and latitude $11^{\circ} 56^{\prime} \mathrm{N}$. It shares its western boundary with Warawa LGA to the northwest and Dawakin Kudu LGA to the southwest. It is bounded to the south and southeast by Garko LGA and on the east by Albasu LGA (southeast), Gaya (east) and Ajingi, northeast and north (see Figure 1).

Wudil Local Government have two Tertiary Institutions of which Polac is one of them, and it's a regimented Institution which embodies a rich diversity of cadets from the 36 states and Capital of the country.

\subsection{Procurement of Samples and Experimentation}

\section{Procurement of Plant Samples}

Matured Bush tea plants (Hyptis Suaveolen) (L.) poit were freshly harvested around Wudil community in Kano and were taken to the Department of Biological Sciences in Polac for identification. The plant samples collected were then divided into two portions, one fresh and the other was dried in the laboratory 


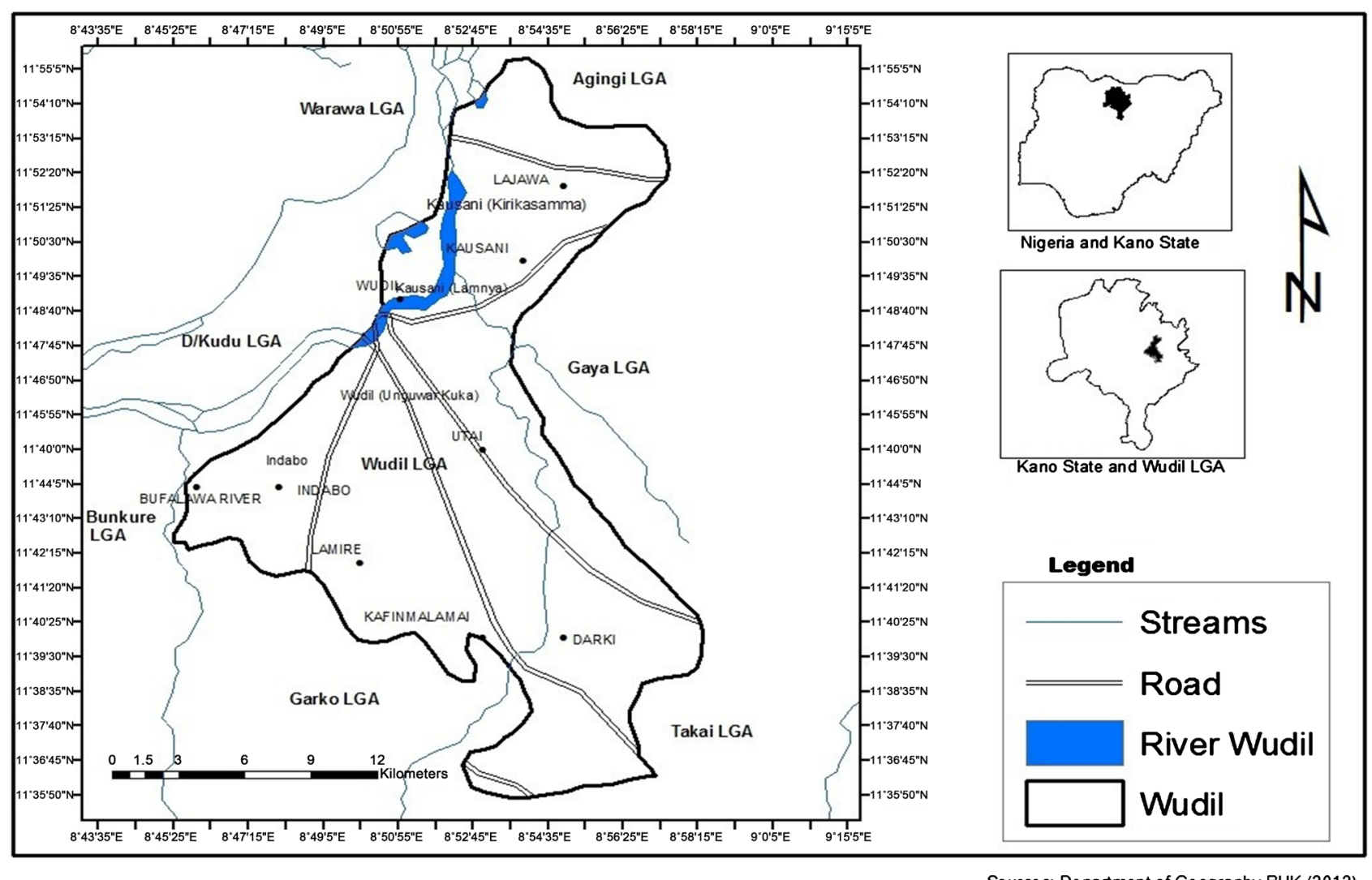

Figure 1. Showing Wudil LGA (the study area).

under ambient temperature.

\subsection{Experimental Units Design, Rearing and Treatment}

\subsubsection{Experimental Units Design and Rearing of Mosquitoes}

Three experimental units of $2 \times 2 \mathrm{~m}^{2}$ were established around the sampling areas in enclosures of within the Cadets' Hostels, another within the Lecture Halls', and the last around the Administrative Block of the Academy. Within each unit were also three sub units (stands) marked A, B and C (i.e. the first-two as test stands and a control respectively) amounted up to 9 replicated units, which were covered with white untreated mosquito nets, with their floor covered with white rubber carpet for attraction of mosquito vectors to their breeding sites, and easy identification and collection of the mosquito specimens that fell to the floor as a result of the effect from the plant specimens that were introduced. In each of the stand, one black mosquito-breeding vessel containing water and organic substances was placed for breeding and rearing of mosquitoes (see Figure 2). The breeding vessels were first left open for one week for mosquitoes to lay eggs, hatched and developed into adult.

\subsubsection{Treatment with the Test Plant (Hyptis suaveolen) (L.) Poit}

The plant samples collected were divided into two portions, one fresh and the other was dried in the laboratory under ambient temperature. In each experimental unit, the harvested plant samples were introduced at the same quantities for both portions. At each unit, the fresh portion was introduced in stand $\mathrm{A}$, and the dried portion was introduced in stand B as seen in Figure 3. Stand C serving as the control was not treated with the test plant. The test plants were introduced in to the stands at various quantities $(\mathrm{kg}) \mathrm{of}$ $1,2,3,4$ and 5. Measurement of the test plant was done using spring balance. Mortalities of dead mosquitoes were recorded at different time of the day (i.e. morning, afternoon and evening) for each treatment 


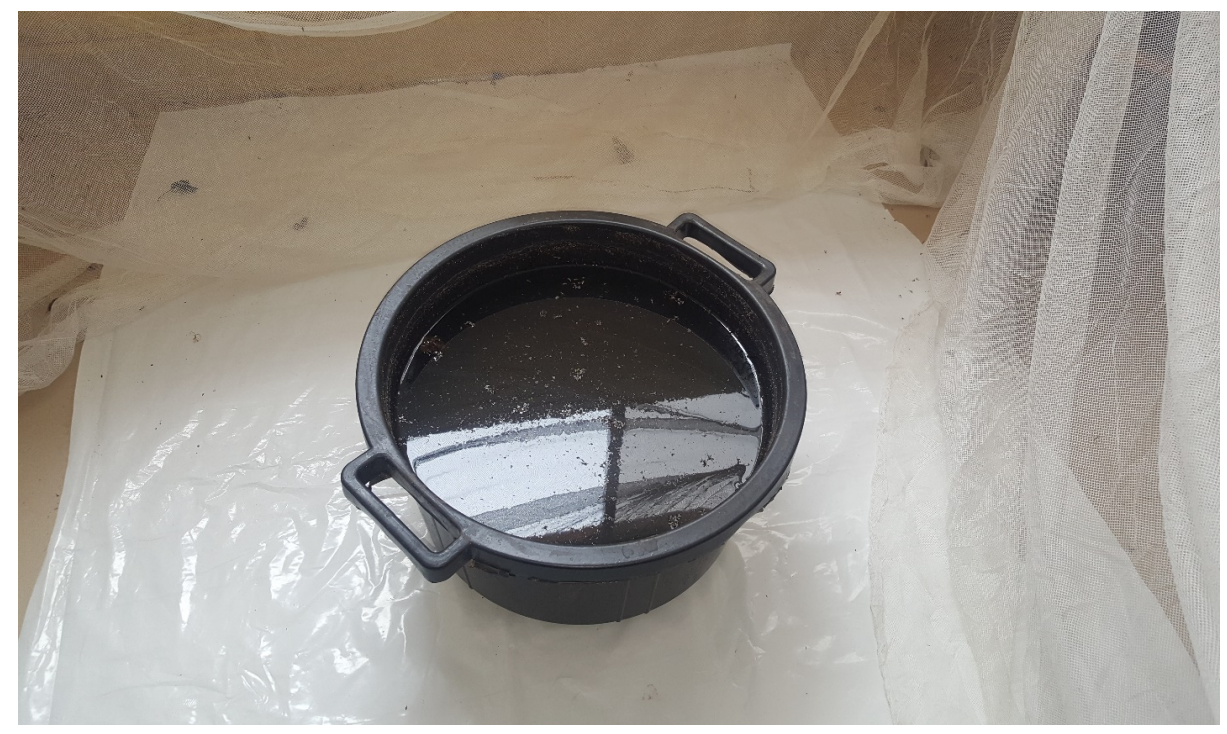

Figure 2. Showing Mosquitoes breeding vessel within the setup.

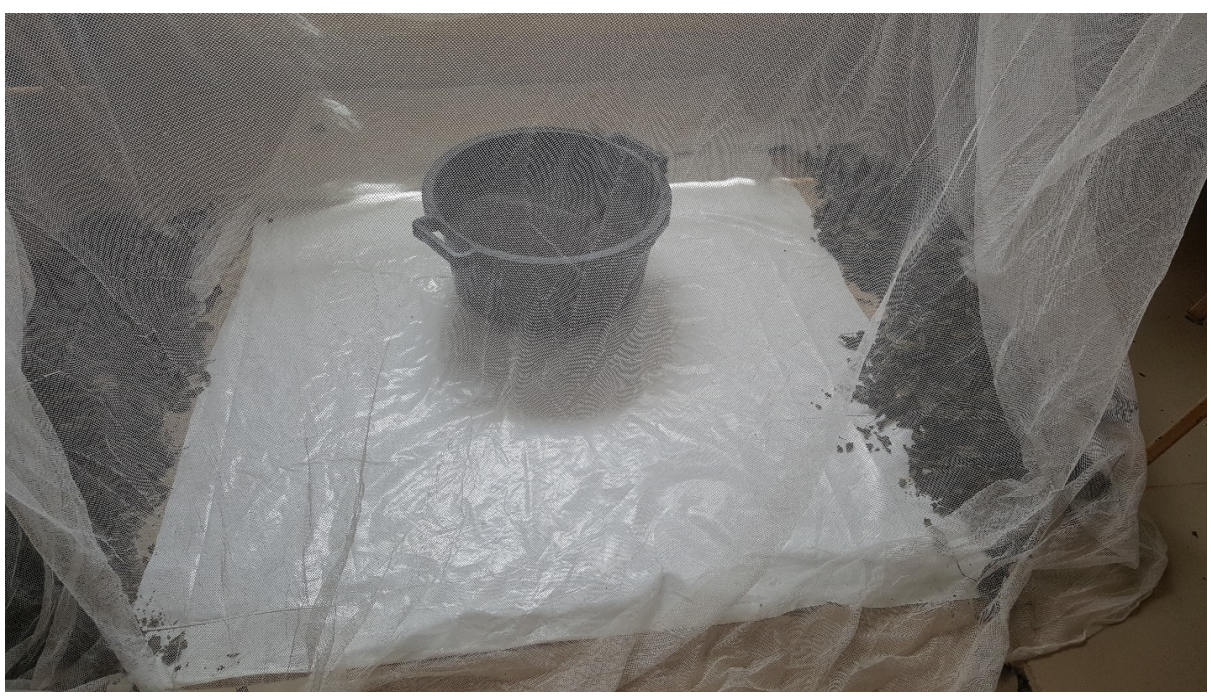

Figure 3. Main experiment with the test plant (Hyptis suaveolens).

(i.e. fresh and dried portion) of Hyptis suaveolens. The \% Mortality Rate (MR) of mosquitoes at each Experimental unit was determined using standard procedures by [15].

\subsection{Statistical Analysis}

Spearman correlation (r) analysis were performed to determine whether there is a coexisting relationship between the quantities of the test plant (H. suaveolens) and the Mortality Rate of mosquitoes in relation to different time of the day.

\section{RESULT}

\subsection{Result of the Percentage Mortality Rate of Mosquito Vectors Recorded at Different Experimental Units during the Study}

The result for mortality rate of mosquito vector recorded at different Experimental Units during the 
study is represented in Table 1 . The result revealed that out of 370 observed mosquitoes treated with portions (i.e. fresh and dried) of the test plant (H. suaveolens), a total of 253 were recorded dead, and a total of 117 were still alive within 24 hours of observation. The result from the three experimental units also showed that, the Administrative Block had recorded significantly highest (86.8)\% mortality rate, followed by cadets' hostel (67.4)\%, while relatively lowest (63.7)\% mortality rate was recorded in the lecture halls.

\subsection{Distribution of the Number of Death Mosquito Vectors in Relation to the Quantity (kg) of the Test Plant}

Table 2 shows the result of the distribution death rate of mosquitoes in relation to different times of the day. The result revealed a relative highest number of death in the afternoon at all the experimental units after application of the test plant (H. suaveolens), given a total of 119 dead adult mosquitoes, followed by evening with a total of 89 dead adult mosquitoes. While the lowest number of death occurred in the morning with a total of 45 .

\subsection{Comparative Effects of Various Quantities of Fresh and Dried Portions of Hyptis suaveolens on the Mortality Rate of Adult Mosquitoes Vector}

The result of the comparative effect of various quantities of Fresh and Dried portions of $H$. suaveolens on mosquito vectors is represented in Table 3. The result had revealed a pattern which shows that, the higher the quantity $(\mathrm{kg})$ of both portions of the test plant, the higher the mortality rate. When the quantity

Table 1. Percentage mortality rate of mosquito vectors recorded at different experimental units during the study.

\begin{tabular}{ccccc}
\hline Experimental Units & $\begin{array}{c}\text { Observed Adult } \\
\text { Mosquitoes }\end{array}$ & $\begin{array}{c}\text { Death recorded per } \\
\text { Unit after Treatment }\end{array}$ & $\begin{array}{c}\text { Survived Adult } \\
\text { Mosquitoes }\end{array}$ & \% M.R \\
\hline Cadet's hostels & 230 & 155 & 75 & 67.4 \\
Lecture halls & 102 & 65 & 37 & 63.7 \\
Administrative Block & 38 & 33 & 5 & 86.8 \\
Total & 370 & 253 & 117 & 217.9 \\
\hline
\end{tabular}

Note: $\%$ M.R = Percentage Mortality Rate.

Table 2. Distribution of the Number of Death of Mosquito Vectors in relation to time of the day.

\begin{tabular}{|c|c|c|c|c|c|c|c|c|}
\hline \multirow{3}{*}{ Experimental Units } & \multirow{3}{*}{$\begin{array}{l}\text { No. of Control } \\
\text { Mosquitos }\end{array}$} & \multicolumn{6}{|c|}{ Obs. in relation to time of the day } & \multirow{3}{*}{ Total D.R } \\
\hline & & \multicolumn{2}{|c|}{$\mathrm{Mn}$} & \multicolumn{2}{|c|}{ Af. } & \multicolumn{2}{|c|}{ Ev. } & \\
\hline & & $\mathrm{Al}$ & Dt. & Al. & Dt. & Al. & Dt. & \\
\hline Cadets Hostel & 115 & 230 & 30 & 200 & 70 & 130 & 55 & 155 \\
\hline Lecture Hall & 51 & 102 & 10 & 92 & 32 & 60 & 23 & 65 \\
\hline Administrative Block & 19 & 38 & 5 & 33 & 17 & 16 & 11 & 33 \\
\hline Total & & \multicolumn{2}{|c|}{45} & \multicolumn{2}{|c|}{119} & \multicolumn{2}{|c|}{89} & 253 \\
\hline
\end{tabular}

Note: Obs. = Observation, Mn. = Morning, Af. = Afternoon, Ev. = Evening, Al. = Number Alive, Dt. = Number Dead, D.R = Death Rate. 
Table 3. Comparative effect of various quantities of fresh and dried portions of Hyptis suaveolens on mosquito vectors.

\begin{tabular}{cccc}
\hline \multirow{2}{*}{ QTP (kg) } & \multicolumn{2}{c}{ Mortality Rate at different portions of the Test Plant } & Average Mortality \\
\cline { 2 - 3 } & Fresh & Dried & 6.5 \\
\hline 1 & 8 & 5 & 14 \\
3 & 19 & 11 & 22.5 \\
4 & 28 & 17 & 32.5 \\
5 & 41 & 24 & 46.5 \\
Total & 63 & 37 & 122 \\
\hline
\end{tabular}

Note: QTP = Quantity of Test Plant used, Spearman Correlation $(\mathrm{r})=0.9832$.

of $H$. suaveolens used increased from $1 \mathrm{~kg}$ to $5 \mathrm{~kg}$, mortality rate of 63 for Fresh portion and 37 for dried portions were recorded, given an average mortality rate of 46.5 within 24 hours of observation during the study. More so, the result also showed that, the efficacy of the Fresh portion of the test plant ( $H$. suaveolens) to kill mosquito vectors was more than that of the dried portion, given a total mortality rate of 159 against 94 of the dried portion.

\section{DISCUSSION}

Comparative study on the fresh and dried portions of Hyptis suaveolens plant against mosquito vectors revealed that, both portions (i.e. fresh and dried) have exhibited some toxic effect on mosquito population during the study however, significant $(\mathrm{P}<0.05)$ higher $\%$ mortality rate of mosquitoes was recorded during the study when the fresh portion of the test plant was applied within the experimental units. The high \% mortality rate of mosquitoes obtained during the study could be as a result of some bioactive ingredients that have been reported to be present in the fresh portion of the test plant, and moreso, as it also possesses strong aromatic property which is found to be due to the presence of certain essential oils, which was similarly reported to have an extensive repellant property on mosquito vectors as insecticide [15-19]. It was certainly observed that, most of the bioactive ingredients and the strong aromatic scent of the plant were lost due to drying. Besides, there was a resultant highest cumulative mortality rate recorded at the cadets' hostels area which could be attributed to high concentration of human population within the area as compared to other experimental units. Since mosquitoes most especially the females need blood meal to aid in fertilization of their eggs $[15,20]$. Also, there was a corresponding increase in overall mortality rate recorded within every experimental unit as the concentration $(\mathrm{kg})$ of the $H$. suaveolens plant introduced into the units also increased which statistically, proves that, there was a strong positive correlative relationship between the quantity of the test plant and the death rate of mosquito vectors, meaning that, there was a strong affinity and efficacy of the quantity of the test plant on the lethal effect on mosquito vectors. This may also be attributed to the fact that the mosquito vectors were confined within the mosquito net surrounding the set ups at the experimental units, and since the test plant $H$. suaveolens has also been reported to have offensive odor which might have affect the olfactory system of the mosquito vectors within the confined set ups that could result their death $[15,21]$.

\section{CONCLUSION}

Over the years, indigenous people have learned to tackle insects' problems through the use of plant 
extracts due to their resistance against chemical insecticides as well as the detrimental effects of the chemical insecticides on non-target organisms and human health problems. Hyptis suaveolens is one among such plant species used locally in rural areas as repellent for biological control of mosquitoes with minimal of those challenges [16]. Based on the aforementioned challenges, the research work was designed to determine the lethal effect of dried and fresh portions of $H$. suaveolens plant on mosquito population with the hope that a new and more effective product may be developed from it. At the end of the study, it was observed that, the quantity (concentration) of the test plant $(H$. suaveolens) had a strong affinity $(\mathrm{r}=$ 0.9832) with the mosquito vectors resulting to their large mortality rate irrespective of the time of the day.

\section{ACKNOWLEDGEMENTS}

Our heartfelt appreciation goes to the management of Nigeria police Academy wudil Kano and that of TETFUND for their great financial support which resulted to the successful completion of this research. We also sincerely acknowledged the vital contributions of Asp, George Mbeh and Abdullateef Isah of the Department of Biological Science for their scholarly contributions that also lead to the successful completion of the lead research.

\section{CONFLICTS OF INTEREST}

The authors declare no conflicts of interest regarding the publication of this paper.

\section{REFERENCES}

1. Radhika, D., Ramathilaga, A., SatheshPrabu, C. and Murugesan, A.G. (2011) Evaluation of Larvicidal Activity of Soil Microbial Isolates (Bacillus and Acinetobactor sp.) against Aedesaegypti (Diptera: Culicidae): The Vector of Chikungunya and Dengue. Proceedings of the International Academy of Ecology and Environmental Sciences, 1, 169-178.

2. Achs, J. and Malaney, P. (2002) The Economic and Social Burden of Malaria. Nature, 15, 680-685. https://doi.org/10.1038/415680a

3. Duke, J.A. (2007) Phytochemical and Ethonobotanical Databases. American Journal of Ethnonobotanicals, 4, 324-329.

4. Olliaro, P., Catani, J. and Wirth, D. (1996) Malaria the Submerged Disease. JAMA, 275, 320-323. https://doi.org/10.1001/jama.1996.03530270070034

5. Poopathi, S. and Tyagi, B.K. (2006) The Challenge of Mosquito Control Strategies: From Primordial to Molecular Approaches. Biotechnology and Molecular Biology Review, 1, 51-65.

6. Das, N.G., Goswami, D. and Rabha, B. (2007) Preliminary Evaluation of Mosquito Larvicidal Efficacy of Plant Extracts. Journal of Vector Borne Diseases, 44, 145-148.

7. Zhang, W.J., Jiang, F.B. and Ou, J.F. (2011) Global Pesticide Consumption and Pollution: With China as a Focus. Proceedings of the International Academy of Ecology and Environmental Sciences, 1, 125-144.

8. Legner, E.F. (1995) Biological Control of Diptera of Medical and Veterinary Importance. Journal of Vector Ecology, 20, 59-120.

9. Becker, N. and Ascher, K.R.S. (1998) The Use of Bacillus thuringiensis sub sp. israelensis (Bti) against Mosquitoes, with Special Emphasis on the Ecological Impact. Israel Journal of Entomology, 32, 63-69.

10. Chapman, H.C. (1974) Biological Control of Mosquito Larvae. Annual Review of Entomology, 19, 33-59. https://doi.org/10.1146/annurev.en.19.010174.000341

11. Murugesan, A.G., Sathesh, P.C. and Selvakumar, C. (2009) Biolarvicidal Activity of Extracellular Metabolites of the Keratinophilic Fungus Trichophyton mentagrophytes against Larvae of Aedesaegypti a Major Vector for Chikungunya and Dengue. Folia Microbiologica, 54, 213-216. https://doi.org/10.1007/s12223-009-0034-5 
12. Kaya, H.K. and Gaugler, R. (1993) Entomopathogenic Nematodes. Annual Review of Entomology, 38, 181-206. https://doi.org/10.1146/annurev.en.38.010193.001145

13. Mittal, P.K. and Subbarao, S.K. (2003) Prospects of Using Herbal Products in the Control of Mosquito Vectors. ICMR Bulletin, 33, 1-10.

14. Nwabor, O.F. (2014) Larvicidal Activity of Picralimanitida: An Approach in Malarial Vector Control. University of Nigeria Virtual Library, Nsukka.

15. Hemen, T.J., Johnson, J.T., Ujah, O.F. and Udenze, E.C.C. (2013) Ethnobotanical Effect of Hyptis suaveolens Plant on Mosquito Species Population in Guinea Savanna, Nigeria. Pharma Science Monitor. An International Journal of Pharmaceutical Sciences, 4, 249-251.

16. Calvalcanti, E.S.B., Morris, S.M., Lima, M.A.A. and Santana, E.W.P. (2004) Larvicidal Activity of Essential Oils from Brazillian Plants against Aedesaegyptic (L.). Memorias do Instituto Oswaldo Cruz, 99, 541-544. https://doi.org/10.1590/S0074-02762004000500015

17. Amusan, A.S., Idowu, A.B. and Arowolo, F.S. (2005) Comparative Toxicity Effect of Bush Tea Leaves (Hyptis suaveolens) and Orange Peel (Citrus sinensis) Oil Extract on Larvae of the Yellow Fever Mosquito Aedes aegypti. Tanzania Health Research Bulletin, 7, 174-178. https://doi.org/10.4314/thrb.v7i3.14256

18. Arivoli, S. and Samuel, T. (2012) Larvicidal Efficacy of Strychnos nuxvomica Linn. (Loganiaceae) Leaf Extracts against the Filarial Vector Culex quinquefasciatus Say (Diptera: Culicidae). Lloydia, 41, 234-239.

19. Ayange-kaa, A.B., Hemen, T.J. and Onyezili, N. (2015) The Effect of Dried Leaves Extract of Hyptis suaveolens on Various Stages of Mosquito Development in Benue State, Nigeria. Journal of Pharmacy and Biological Sciences, 6, 28-32.

20. Lyimo, E.O. and Takken, W. (1993) Effects of Adult Body Size on Fecundity and the Pregravidrate of Anopheles gambiae Females in Tanzania. Medical and Veterinary Entomology, 7, 328-332. https://doi.org/10.1111/j.1365-2915.1993.tb00700.x

21. Wagner, W.L., Herbst, D.R. and Sohmer, S.H. (1999) Manual of the Flowering Plants of Hawai. University of Hawai Press, Honolulu, 102-108. 